\title{
Integrated Learning Experience Through Activity Based Learning in UG Course
}

\author{
N. Vijaya kumar ${ }^{1}$, Praveen Kumar Petkar ${ }^{2}$, Madhusudhana H K ${ }^{3}$, G Jangali Satish ${ }^{4}$ \\ ${ }^{1,2,3,4}$ School of Mechanical Engineering, KLE Technological University, Hubballi-580031, Karnataka, India \\ 1vijaykumar@kletech.ac.in \\ 2 praveenkumar@kletech.ac.in \\ ${ }^{3}$ hkmadhu30@gmail.com \\ ${ }^{4}$ jsatish@kletech.ac.in
}

\begin{abstract}
:
Academic institutions worldwide focused on providing a platform for students' integrated learning experience to enhance their skills and increase employability. School of Mechanical Engineering is making continuous efforts to provide integrated learning experiences for UG program students by designing Integrated Learning experience by activitybased learning approach. This work aims to provide integrated knowledge of courses such as manufacturing Technology and Metrology, which are part of the curriculum. The course Manufacturing Technology and Metrology and Quality engineering are considered for this work. These courses' knowledge plays a vital role in students' professional lives when employed in manufacturing industries. This initiative's main objectives are to provide an integrated learning experience, i.e., integration of manufacturing and measurement process, which are essential stages of product development. An Activity is given to the students to compare and analyze the process capabilities of traditional and advanced
\end{abstract}

\section{N. Vijaya kumar}

School of Mechanical Engineering,

KLE Technological University, Hubballi, Karnataka, India vijaykumar@kletech.ac.in machine tools such as conventional Lathe and Computer Numerical Control(CNC). One batch of students used a conventional lathe machine, and the other batch used the CNC lathe machine. The students manufactured the part and collected the data (dimensions) about the part, analyzed the data through MINI-TAB software, and finally concluded about traditional and advanced machines' capabilities to manufacture parts according to specification. Through this, the students can establish integrated knowledge between the Manufacturing Technology and Metrology and Quality Engineering courses they have learned in isolation. These courses spread across different semesters. The performance indicators (PIs) of the graduate attribute (GA) of ABET program outcome ' 4 ' were underlying the motivators while designing the activity

Keywords: Integrated Learning, Activity Based Learning, Manufacturing Process, Metrology, UG Program.

\section{Introduction}

In today's world, knowledge and information exchange, Creativity, adaptability, critical reasoning, and collaboration are highly valued skills. When it comes to fostering those skills in the classroom, integrated Learning is an instrumental approach that helps students develop multifaceted expertise and grasp the vital role in establishing interrelationships between concepts.[1]. Integrated Learning, 
sometimes called interdisciplinary studies, bring together diverse disciplines in a comprehensive manner, enabling students to develop a meaningful understanding of the concepts. The several works published showed that the integrated learning experience was brought by restructuring curriculum, mini, and a capstone project. The authors believed that the vertical integration of courses in the curriculum threads provided an opportunity to integrate the knowledge and skills required in solving complex engineering problems through mini and capstone projects . Another way of giving an integrated learning experience for students is to through a course project. The authors have proposed a model. The Integrated Course Project Model will integrate multiple courses through a single integrated project, enhancing the design, communication, lifelong learning, etc., among students. Open-ended problems in laboratory experiments play vital roles in enhancing the student's knowledge. In open-ended experiments, students have the flexibility to develop their own experiments [16].

Apart from providing an integrating learning experience through mini, capstone, and course projects, Activity Based learning is another way to integrate the courses learned in isolation. Experiential Learning [10] and Activity-based Learning is an active mode of Learning which overcomes the traditional way of Learning. The traditional way of Learning is dominated by monotonous delivery of lectures without having an activity. There are several ways of implementing activity-based learning, such as Think-Pair-Share, Role Play, Game-based Learning, debates, hands-on activity, etc.

The engineering program aims to provide the integrated Learning experience and training to honor degree students who intend to seek a mechanical engineering career. To achieve integration, the problem-solving approach suggested by Cowley should be introduced into the curriculum[11]. The present work focuses on providing an integrating Learning experience for undergraduate students by designing activity-based Learning through hands-on experience activity where students are involved in manufacturing specimens and measurement of process capability. This Activity help students to undergo experiential Learning.

In the product manufacturing process, manufacturing and measurement are the essential processes. In the Mechanical engineering
Curriculum, manufacturing technology and measurement process are taught in different courses. To provide an integrating learning experience, an activity is planned to fill this gap. The student's problem is to study machines' process capability with the criteria that the different batches have to select different machines and perform the capability study. This primary objective is to study different machines with differences in technologies to compare traditional and advanced technologies' capabilities through process capability analysis.

Process Capability Study (PCS): PCS is a procedure used to control product manufacturing. PCS to detect and eliminate the causes of variation in the process [6]. Process capability helps to determine the ability to manufacture parts within the tolerance limits. There are several capability indices [7, 8], including $\mathrm{CP}, \mathrm{C}_{\mathrm{PU}}, \mathrm{C}_{\mathrm{PL}}$, and $\mathrm{C}_{\mathrm{Pk}}$, which are calculated, as shown in Table 1. Figure 1 shows the spread of the process from the Mean of $\overline{\bar{X}}$ where: Upper Specification Limit (USL), Lower Specification Limit (LSL), $\overline{\bar{X}}=$ Mean of the process and $\sigma=$ Standard Deviation of the Process. The product with a dimension above the upper specification limits subjected to rework. A product with a dimension that falls below the lower specification limit is to be treated as scrap. If product dimensions fall between these limits, they are nondefective products.

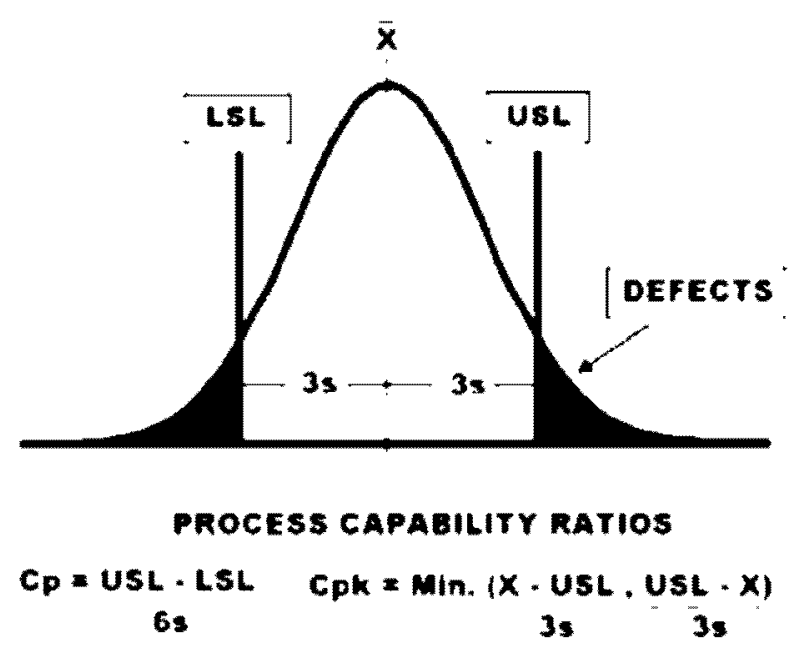

Fig. 1: Spread of the process (Source: Pin on Lean Six Sigma)

The process capability to meeting specifications can be analyzed by determining the value of $\mathrm{Cp}$ and $\mathrm{CPk}$, which is as shown in Table land Table 2. 
Table 1: Equations Quantifying

Process Capability [7,8]

\begin{tabular}{|c|c|l|}
\hline Index & Equation & Usage \\
\hline$C p$ & {$\left[\frac{U S L-L S L}{6 \sigma}\right]$} & $\begin{array}{l}\text { Process Capability for - } \\
\text { Two-sided Specification } \\
\text { limit, irrespective of } \\
\text { Process Centre }\end{array}$ \\
\hline$C p u$ & {$\left[\frac{U S L-\overline{\bar{X}}}{3 \sigma}\right]$} & $\begin{array}{l}\text { Process Capability relative } \\
\text { to Upper Specification } \\
\text { Limit }\end{array}$ \\
\hline$C p L$ & {$\left[\frac{\bar{X}-L S L}{3 \sigma}\right]$} & $\begin{array}{l}\text { Process capability relative } \\
\text { to lower specification } \\
\text { limit. }\end{array}$ \\
\hline$C p k$ & $\min \left[\frac{\left.U S L-\stackrel{\bar{X}}{3 \sigma}, \frac{\bar{X}-L S L}{3 \sigma}\right]}{3 \sigma}\right]$ & $\begin{array}{l}\text { Process Capability for } \\
\text { two-sided Specification } \\
\text { limits accounting for } \\
\text { process centering }\end{array}$ \\
\hline
\end{tabular}

Table 2 : Process capability index values

\begin{tabular}{|l|l|}
\hline $\begin{array}{l}\text { Capability } \\
\text { index }\end{array}$ & Estimation of the process \\
\hline $\mathrm{C}_{\mathrm{p}}=1, \mathrm{Cpk}=1$ & $\begin{array}{l}\text { The process is marginally meeting } \\
\text { the specification }\end{array}$ \\
\hline $\mathrm{C}_{\mathrm{p}}, \mathrm{Cpk}<1$ & $\begin{array}{l}\text { The process is not capable of meeting } \\
\text { Specification. }\end{array}$ \\
\hline $\mathrm{C}_{\mathrm{p}}, \mathrm{C}_{\mathrm{Pk}}>1$ & $\begin{array}{l}\text { The process is capable of Meeting Specification } \\
\text { Limit }\end{array}$ \\
\hline
\end{tabular}

\section{Objectives}

This initiative aims to build competency among the students towards solving industrial quality-related issues. The specific objectives are as follows:

- To establish the integration between the Manufacturing and Measurement courses.

- To compare the capabilities of traditional and advanced machines

- To engage in lifelong learning, including learning in the workplace.

- To design, collect data, organize, analyze, and interpret the experimental results.

\section{Mapping of Course Outcomes with Program Outcomes for Integrated Learning experience.}

The Specific Course Outcomes and mapping with program outcomes for the integrated learning experience through activity-based learning are depicted in Fig 2.

\begin{tabular}{|c|c|c|c|c|c|c|c|c|c|c|c|c|c|}
\hline \multirow{2}{*}{$\begin{array}{l}\text { Course Outcomes (COs) / Program } \\
\text { Outcomes (POs) }\end{array}$} & \multicolumn{13}{|c|}{ Program Outcomes } \\
\hline & 1 & 2 & \begin{tabular}{l|l}
3 & 4
\end{tabular} & 5 & 6 & 78 & 9 & 10 & 11 & 12 & 13 & & 14 \\
\hline \multicolumn{14}{|l|}{$\begin{array}{l}\text { Metrology and Quality Engineering } \\
\text { Course }\end{array}$} \\
\hline $\begin{array}{l}\text { Analyze and Compare the process } \\
\text { capabilities of Traditional and } \\
\text { Advanced Machines through } \\
\text { experiential learning }\end{array}$ & & & $\mathbf{v}$ & & & & & & & & & & \\
\hline \multicolumn{14}{|l|}{ Manufacturing Technology Course } \\
\hline $\begin{array}{l}\text { Write an CNC Program for given } \\
\text { specification of part and Produce a } \\
\text { part under CNC Machine through } \\
\text { activity Based Learning. }\end{array}$ & & & $v$ & & & & & & & & & & \\
\hline
\end{tabular}

\section{Fig. 2 : Course Outcome Mapping for} integrated Learning Experience

\section{Methodology}

The process followed by students for activitybased learning is depicted in Fig 3 .

Problem Statement:- The problem statement given by faculty to the student is to study the Process capability study of conventional and advanced machines (CNC) machine.

Group Formation and problems selection:Formation of the group has left to the students' discretion, and students have decided to select the problem statement. Each group has selected a problem based on their interest.

Experimental plan for data collection:-Each group of students has selected the problem and have finalized the machine to be studied, part specification, measurement method, and statistical tools for the study.

Part Manufacturing:- The student's group selected problem statement on studying process capability of lathe have machined components according to specification, which is grouped in 7 Subgroups, and each group has 5 parts.

Similarly, another student group selected a problem to study the CNC machine's capability. Initially, a program is written by students to manufacture a part using a $\mathrm{CNC}$ machine. This program is run under a CNC machine, and parts are produced in subgroups of 7, and each subgroup has 5 parts. 


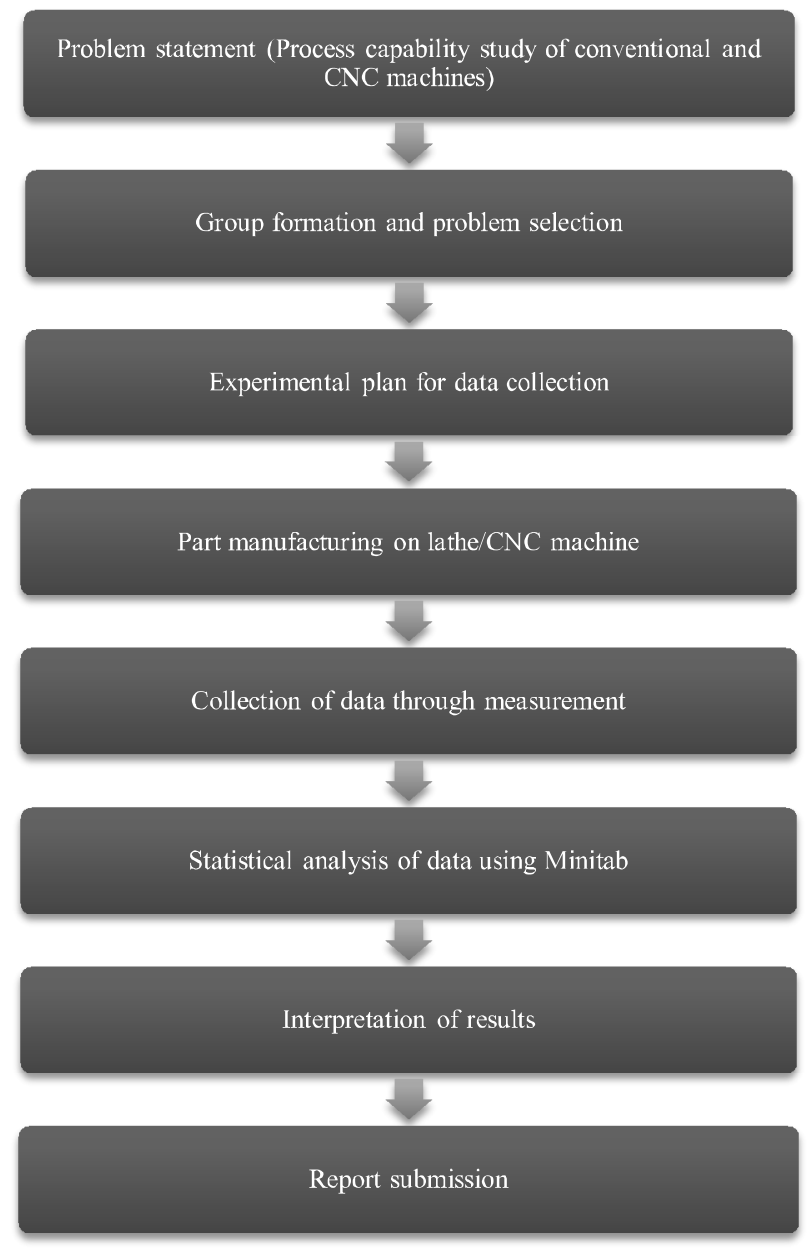

Fig. 3 : The process followed by students in activity-based learning

Collection of data:-Students Group machined the components on the lathe, measured the dimensions of a part using a vernier calliper, and recorded the measurement of part manufactured for analysis. which is as shown in table 3

The group machined the parts on CNC used the advanced measuring instrument FARO Gauge to record the dimensions of part manufactured as shown in table 4

Statistical Analysis and Interpretation of Data:Data collected for both conventional and $\mathrm{CNC}$ machines are analysed using MINI TAB Software[5] to analyse the variation present in subgroups and to know the values of $\mathrm{Cp}$ and $\mathrm{Cpk}$. Knowing the values, students have concluded that the process is capable of producing parts according to customer specifications.

Report submission: Students of each group has submitted a detailed report showing details from problem selection to interpretation of results.

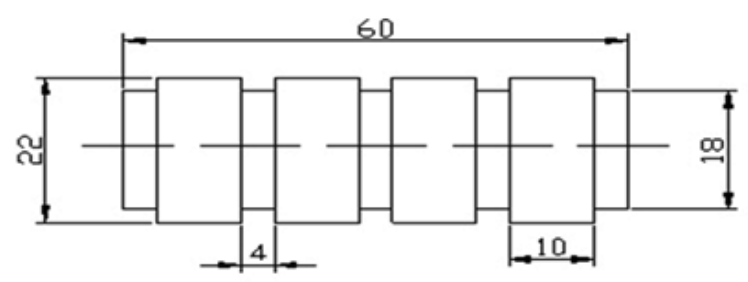

Fig. 4 : Component profile machined using conventional \&CNC Lathe.

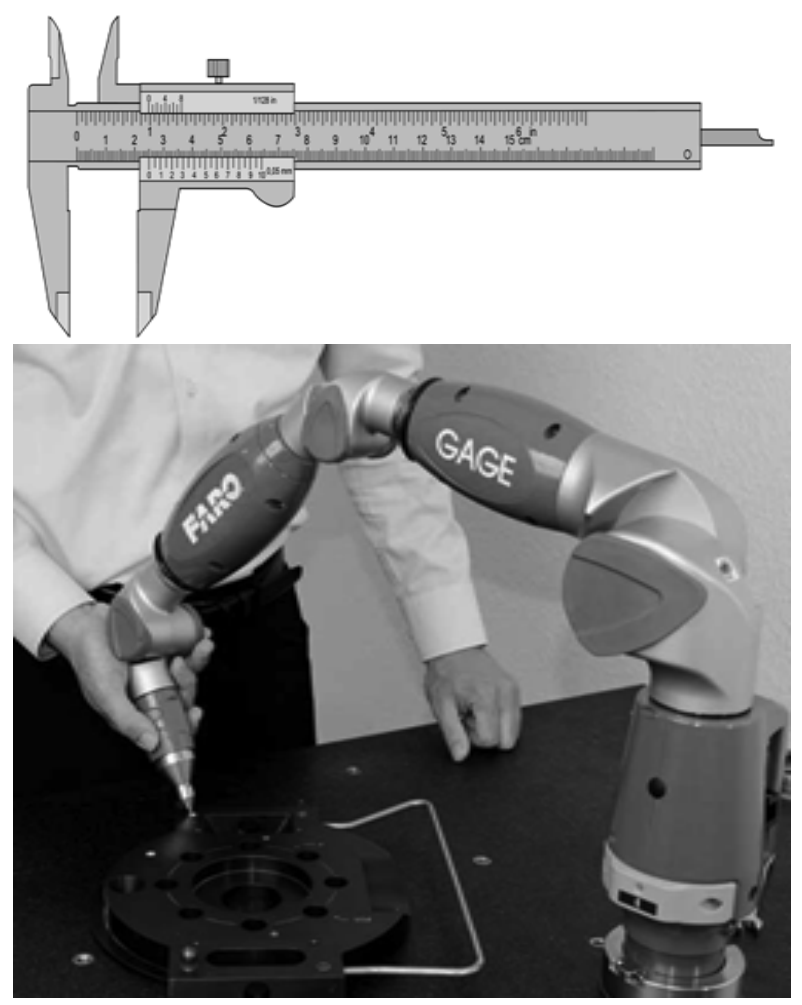

Fig. 5 : Vernier caliper and FARO GAUGE used for measurement of components

\section{Result and Discussion}

The details of the work done by the students are presented below:

4.1. Process Capability Analysis in Turning Operation (Conventional Lathe Machine)

The group of students who have performed a process capability study of lathe machine in a machine shop has been presented in this section. This study investigates the process's capability to meet the customer specification requirement in machining 
(Step turning operation) on a conventional lathe machine. Two groups of students themselves carried out the machining operation according to the part's specification using a lathe machine. The data presented here is work carried by one group of students. Samples ( 35 nos grouped in 7 subgroups of five components in each subgroup) were turned to achieve a target dimension. Accordingly, each component dimension was measured using a vernier calliper, and the collected data was then analysed using MINITAB software to know the process capability indices. The experimental data for the process capability study is shown in Table 3 , and the process capability experimental details are as follows:

Machine used: Toolroom lathe (Conventional) Tool material: Carbide single point Workpiece material: Mild Steel. The diameter of a raw material = $22 \mathrm{~mm}$ the required target diameter $=18 \mathrm{~mm}$ Tolerance selected for turning $= \pm 1 \mathrm{~mm}$.

Table 3 : Measurement data of component machined under the conventional lathe

\begin{tabular}{|c|c|c|c|c|c|c|c|}
\hline \multirow{2}{*}{$\begin{array}{c}\text { Batch } \\
\text { No. }\end{array}$} & \multicolumn{5}{|c|}{ Measurement of Step diameters } & \multirow{2}{*}{$\underset{\text { Average }}{\bar{X}}$} & \multirow{2}{*}{\begin{tabular}{l}
\multicolumn{1}{c}{$\mathbf{R}$} \\
Range \\
(Highest \\
-Lowest
\end{tabular}} \\
\hline & A1 & $\mathbf{A 2}$ & $\mathbf{A 3}$ & A4 & A5 & & \\
\hline 1 & 18 & 18 & 18 & 18 & 18 & 18 & 0 \\
\hline 2 & 18 & 18.2 & 18 & 18 & 18 & 18.06 & 0.2 \\
\hline 3 & 17.8 & 18 & 18 & 18 & 18 & 17.96 & 0.2 \\
\hline 4 & 17.8 & 18 & 18 & 18 & 18 & 17.98 & 0.2 \\
\hline 5 & 18 & 17.6 & 17.4 & 17.6 & 18 & 17.76 & 0.4 \\
\hline 6 & 18 & 17.8 & 17.6 & 18 & 18 & 17.8 & 0.4 \\
\hline 7 & 18 & 18 & 18 & 18 & 18 & 18 & 0.0 \\
\hline
\end{tabular}

After collecting data depicted in Table 3, students Analysed the process capability using the collected data in a statistical software MINI TAB. The students knew Usage of Statistical software; the students have interpreted the results obtained from the software depicted in Fig 6. The result showed a variation from one subgroup to another, as shown in Fig 6. The variations are within the control limits. For conventional lathe, the process capable indices, $\mathrm{CP}$, and CPK for the process capability study are 0.25 and 0.13 .
Hence, this group of students who studied lathe's process capability concluded that the process could not meet the specification limit as $\mathrm{Cp}<1$; therefore, the process will have defective products.

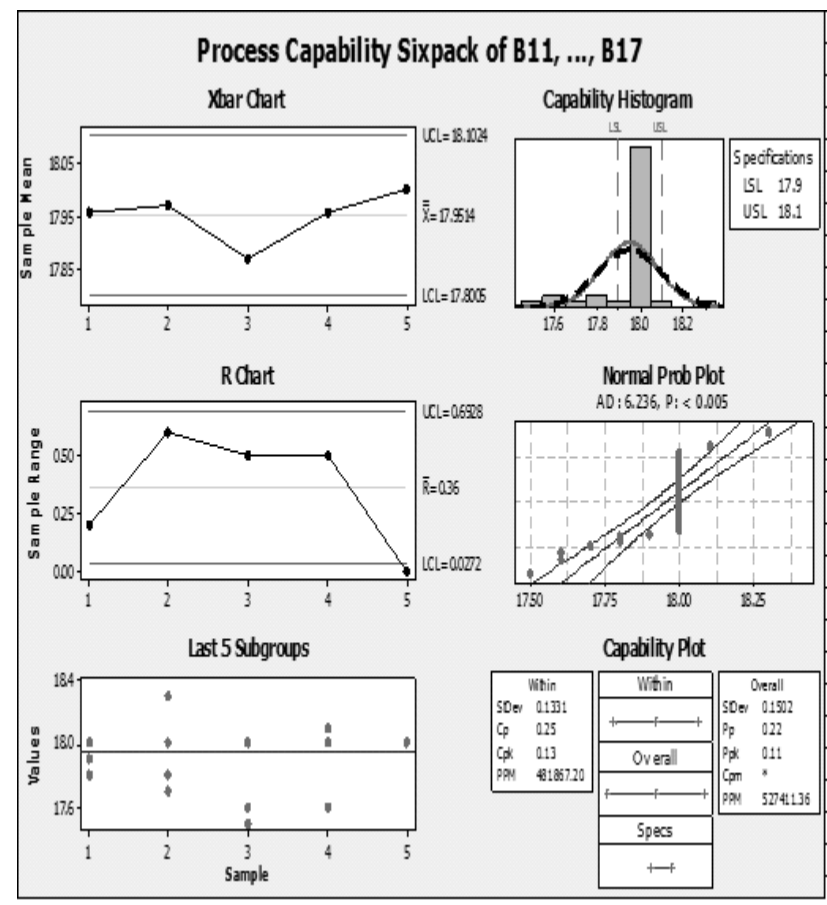

Fig. 6 :Process Capabilities of conventional lathe Machine

4.2 rocess Capability Analysis in Turning Operation (CNC Lathe Machine)

The machine used: CNC Lathe. Tool material: Carbide single point Workpiece material: Mild Steel. The diameter of a raw material $=22 \mathrm{~mm}$. The required target diameter $=18 \mathrm{~mm}$

Tolerance selected for turning $= \pm 1 \mathrm{~mm}$.

This section discusses the group of students who have studied the process capability of the CNC Lathe machine

The component, shown in Fig 4 to produce part under the CNC Lathe machine following program, is written by students as shown in Fig.7.The student already studied the concept $\mathrm{CNC}$ part program in the manufacturing technology course. The components are machined in a CNC machine, and the measurement data are collected to analyse process capability, which is as shown in Table 4. The measurement data collected are analysed for process capability using MINI TAB software. 


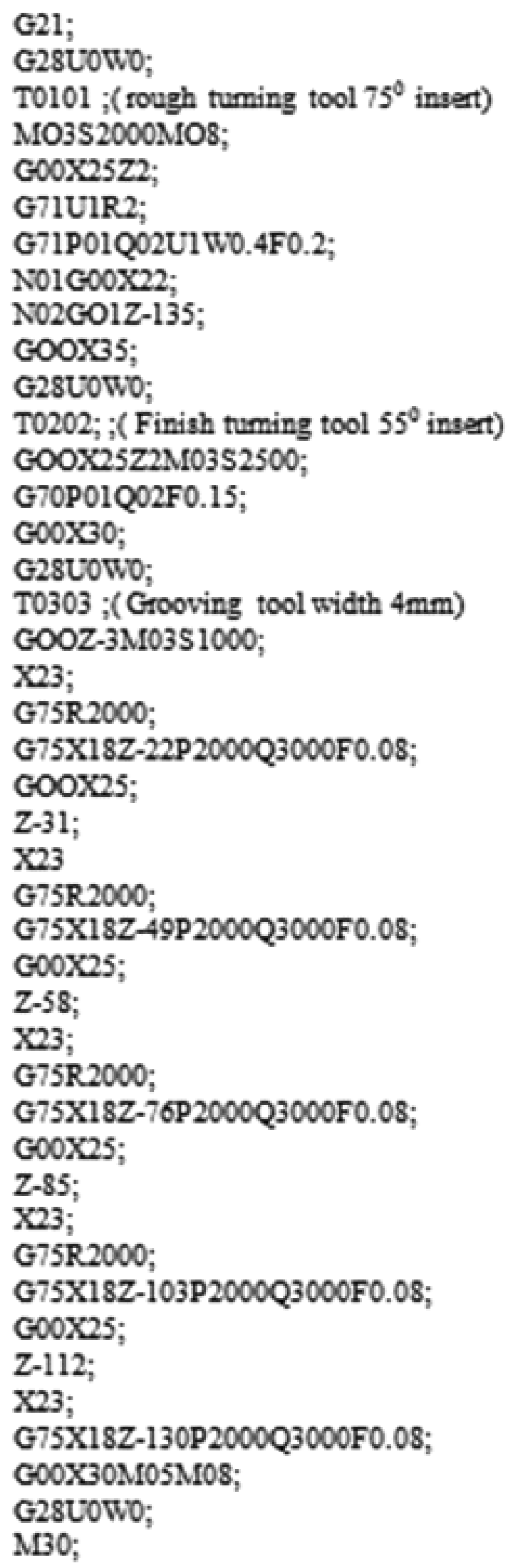

Fig. 7 : CNC Program
Table 4 : Measurement data of component machined under CNC Lathe Machine

\begin{tabular}{|c|l|l|l|l|l|l|l|}
\hline \multirow{2}{*}{$\begin{array}{c}\text { Batc } \\
\text { h No }\end{array}$} & \multicolumn{5}{|c|}{ Measurement of Step diameters } & \multirow{2}{*}{} & \multirow{2}{*}{$\mathrm{R}$} \\
\cline { 2 - 7 } & A1 & A2 & A3 & A4 & A5 & & \\
\hline 1 & 18.0 & 18.02 & 18.0 & 18.0 & 18.0 & 18.004 & 0.02 \\
\hline 2 & 18.0 & 18.0 & 18.0 & 18.02 & 18.0 & 18.004 & 0.02 \\
\hline 3 & 18.0 & 18.0 & 18.0 & 18.0 & 18.02 & 18.004 & 0.02 \\
\hline 4 & 18.0 & 18.0 & 18.02 & 18.0 & 18.0 & 18.004 & 0.02 \\
\hline 5 & 18.0 & 18.02 & 18.0 & 18.0 & 18.0 & 18.004 & 0.02 \\
\hline 6 & 18.0 & 18.0 & 18.02 & 18.0 & 18.0 & 18.004 & 0.02 \\
\hline 7 & 18.0 & 18.0 & 18.0 & 18.0 & 18.02 & 18.004 & 0.02 \\
\hline
\end{tabular}

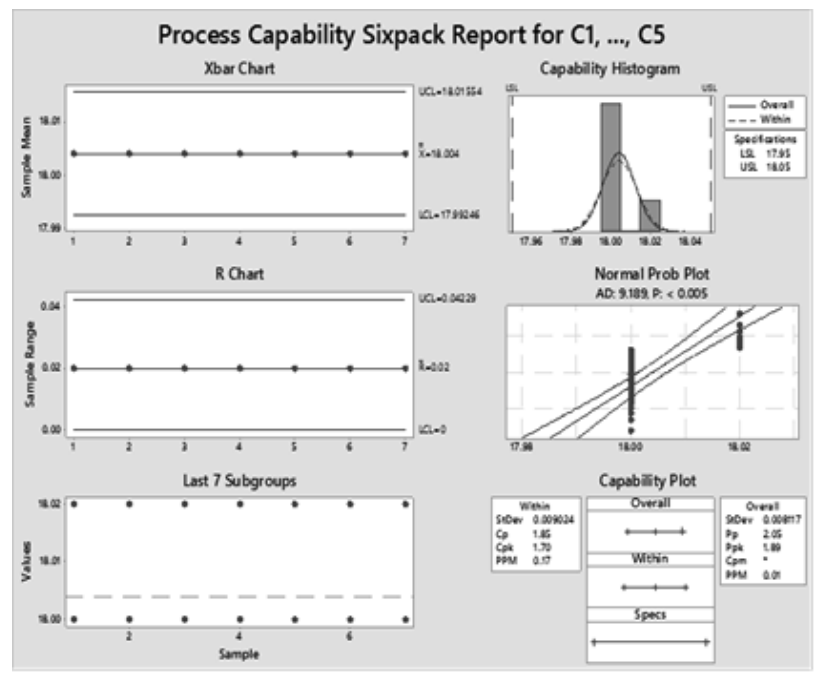

Fig. 8 : Process Capabilities of CNC lathe Machine

Figure 8 depicts the process capability analysis for $\mathrm{CNC}$ lathe machine that variation from one product to another is almost zero. The indices $\mathrm{CP}$ and $\mathrm{CPK}$ for the process capability study show 1.85 and 1.70, respectively. Students have concluded that the process meets specifications $s$ the value of $\mathrm{Cp}$ and $\mathrm{Cpk}$ are $>1$.

4.3 Comparison of Process capabilities of Conventional Lathe and CNC Lathe Machines

To compare the results of conventional and $\mathrm{CNC}$ machine capability. The following criteria's have used for comparison

1. The Main criteria is that process is said to be capable when part variation should be minimum. All dimensions of products plotted should fall between allowable variation between specified limits. (Upper and Lower Control Limit). 
2. The Capability indices depicted in Table 2 are used to decide the process's capability following cases may arise in deciding the process's capability.

- When the value of $\mathrm{Cp}$ or $\mathrm{Cpk}=1$ Process is marginally capable of meeting specification limits, all the products manufactured are accepted. Care should be taken that slight variation in the process may lead to defective product manufacturing.

- If $\mathrm{Cp}$ or $\mathrm{Cpk}<1$, the process cannot meet specification limits; hence, the process has defective.

- If $\mathrm{Cp}$ or $\mathrm{Cpk}>1$, the process meets specification limits; hence, the process has no defects, all the products manufactured are accepted.

The above criteria students have studied in the course metrology and Quality Engineering.

4.4 Students Results Comparison Conventional Lathe Vs. CNC Lathe Machine

It is evident from Figs. 6 and 8 that the components manufactured using $\mathrm{CNC}$ lathe machine have significantly less variation than conventional lathe machines, which has many variations from one subgroup to another subgroup. And it's also evident by $\mathrm{Cp}$ and $\mathrm{Cpk}$ values. Through this activity-based learning, students experienced a hands-on activity. They can appreciate the use of advanced technology machines (CNC and FARO gauge) in terms of accuracy and preciseness.

\section{Attainment of Program Outcomes}

The assessment was done to attain program outcome 4, i.e., conduct investigations of complex problems, the competency and performance indicators (PIs) defined for the outcomes are shown in table 5 .

Students were evaluated for each of the indicators through demonstration, presentation, and viva-voce examination. The attainment for each element of the PO4 outcome is recorded. Students have assessed different elements of program outcomes through rubrics, as shown in the Appendix. The different elements of the rubrics are as follows.

Planning/Designing experiment: - Students planned an experiment to study the process capability of traditional and advanced machines. Students have decided the specification of a part, as shown in Fig 4. Students have Selected appropriate instruments to collect dimensions of the manufacturing component.

Conduction: - Students have manufactured parts themselves in Lathe and CNC. And collected measurement data using measuring instruments and tabulated the results.

Analysis of Data: - The data collected is analysed by the students through MINI TAB software and able to systematically followed the steps in software to get the results for process capability analysis.

Interpretation of Results: -Students have interpreted the results obtained from the MINI TAB and concluded the results obtained. Figure 9 presents the attainment of each of

As the students are assessed based on viva -voce mode, the faculty asked each student questions about their involvement and understanding of the concepts.

The performance is evaluated, and marks are assigned to each student based on the rubrics' weightage.

Fig. 09 showed that the experiment's conduction element of PO has higher attainment of 81.15 than design, analysis, and interpretation. Students showed active involvement as it is hands-on activity-based learning. But whereas the low attainment of the Analyse and interpret element of PO is that some students cannot explain the Usage of tools and procedures followed in software and cannot interpret the software results. Each student's marks are evaluated based on their performance attainment of overall PO 4 is $65.64 \%$. Similarly, PI is evaluated in terms of experimental plan and procedure followed for statistical design and experiment analysis. As 4.2.2 Performance indicator focuses on statistical design of experiments, were the students executed basic steps involved in statstics by collecting data through measurement and organised the data, performed some basic caluculation like Average and Range .The experimental data collected has analyzed in software tool and interpreted the output of anayzed data so from this students able to understand statistical analysis of experimental data and usage of statistical tools. The attainment of 4.2 .2 is $71 \%$ because most students are well-versed with the Usage of tools and knowledge of the statistical concept. 
Table 5 : Competency and performance indicators for program outcome

\begin{tabular}{|l|l|c|l|}
\hline Competency & $\begin{array}{c}\text { PI } \\
\text { Code }\end{array}$ & \multicolumn{1}{|c|}{ Performance Indicators } \\
\hline 4.2 & $\begin{array}{l}\text { Demonstrate } \\
\text { their ability } \\
\text { to design } \\
\text { experiments } \\
\text { to solve } \\
\text { open-ended } \\
\text { /activity- } \\
\text { based } \\
\text { problems }\end{array}$ & 4.2 .1 & $\begin{array}{l}\text { Develop and design } \\
\text { experimental approach, specify } \\
\text { appropriate equipment and } \\
\text { procedures, implement these } \\
\text { procedures, and interpret the } \\
\text { resulting data to characterize } \\
\text { an engineering material, } \\
\text { component, or system. }\end{array}$ \\
\cline { 2 - 3 } & 4.2 .2 & $\begin{array}{l}\text { Understand the importance of } \\
\text { experiments' statistical design } \\
\text { and choose an appropriate } \\
\text { experimental design plan } \\
\text { based on the study objectives. }\end{array}$ \\
\hline
\end{tabular}

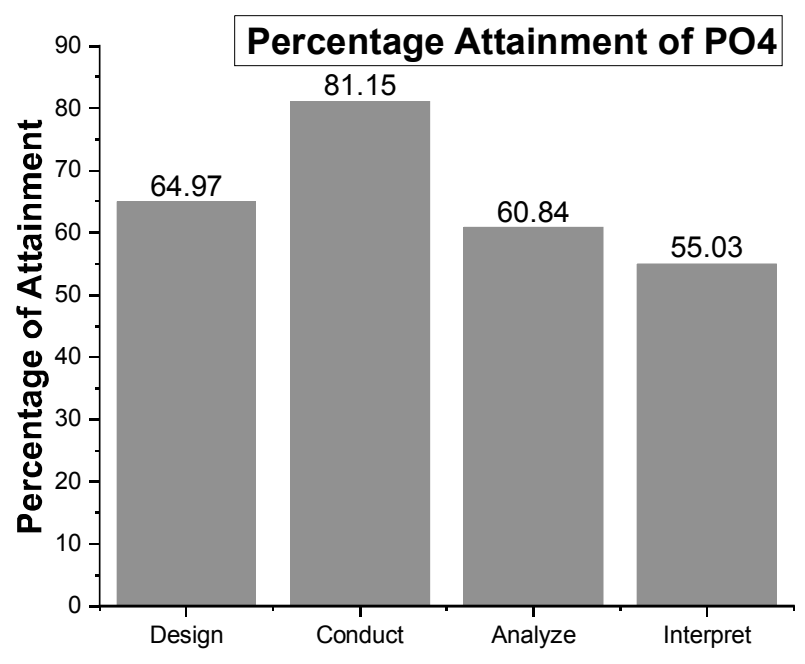

Fig. 9 : Attainment of PO

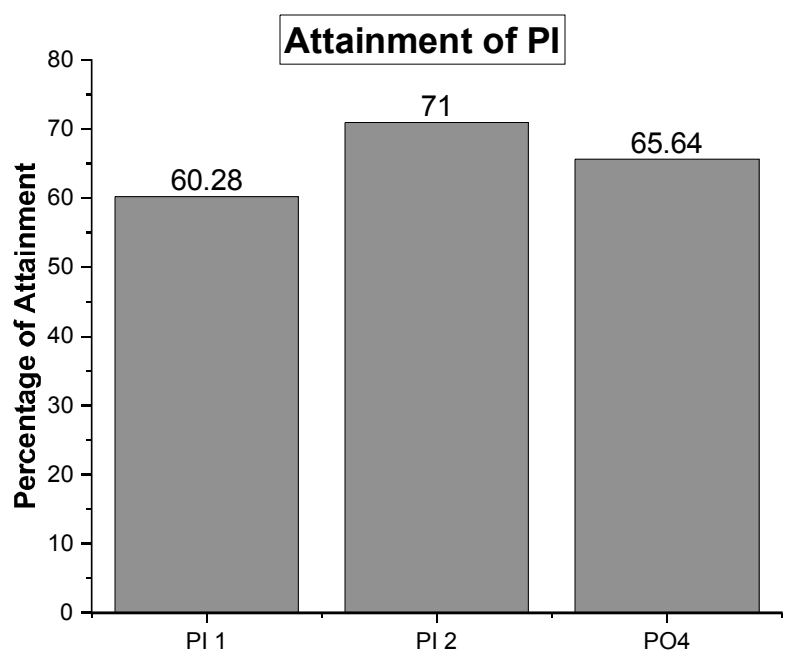

Fig. 10 : Attainment of PI

\section{Conclusions}

Engineering education is continuously seeking ways to show students the importance of Experiential Learning to achieve excellence in their professional practice. This goal is achieved by integrating the concepts learned in different courses, which they have learned in isolation. Designing such an activity helps the student community to understand the concept as they have active involvement. The current initiative in Metrology and Quality Engineering Lab course for UG is an attempt to meet two objectives: To provide an integrated learning experience of manufacturing and measurement concepts studied in isolation. And another is to compare the traditional machine with advanced machine capabilities. The students use the manufacturing process knowledge to produce the component and metrology knowledge to select a suitable instrument for measuring and analyzing the process capability data. Students appreciate the difference in technology through this activity because they have involved themselves in executing this activity.

\section{Acknowledgment}

The authors would like to thank Dr. Ashok Shettar, Vice-chancellor of KLE Technological University, Dr. P. G. Tewari, Principal, BVBCET, Hubli and Dr. B.B. Kotturshettar, Professor and Head, Department of Mechanical Engineering, KLE Technological University, Hubli for their continuous guidance and motivation for this innovative practice. The authors also thank the Instructors of the Machine shop, Learning Factory, and Metrology and Quality Engineering lab for their constant support during this activity's execution.

\section{References}

[1] IP Wai Hung An integrated problem-based learning model for engineering education International journal of engineering education 2003 vol 19 No5. Pp734-737

[2] U. Mudenagudi et al., "Proceedings of the International Conference on Transformations in Engineering Education," Proc. Int. Conf. Transform. Eng. Educ., pp. 359-367, 2015, doi: 10.1007/978-81-322-1931-6.

[3] Savage, R., Chen, K. \& Vanasupa, L. (2008). Integrating Project-based Learning throughout 
the Undergraduate Engineering Curriculum. Journal of STEM Education, 8(3),. Laboratory for Innovative Technology in Engineering Education (LITEE). Retrieved November 29, 2020 from https://www.learntechlib.org /p/173698/.

[4] M. Vijayalakshmi, M. S. Patil, A. S. Nayak, V. S. Handur, and G. S. Hanchinamani, "Enhancing students learning skills through integrated course project design model (ICPDM)," Proc. IEEE 18th Int. Conf. Adv. Learn. Technol. ICALT 2018, pp. 30-33, 2018, doi: 10.1109/ICALT.2018.00014.

[5] U. Patil, S. V. Budihal, S. V. Siddamal, and U. K. Mudenagudi, "Activity Based Teaching Learning: An Experience," J. Eng. Educ. Transform., vol. 0, no. 0, 2016, doi: 10.16920/jeet/2016/v0i0/85433.

[6] Boyles RA (1994). Process capability with symmetric tolerances. Commun. StatisticsSimul. Comput. 23(3): 615-643

[7] Ramakrishnan B, Sandborn P, Pecht M. (2001). Process capability indices and product reliability. Microelectronics Reliability 41, 2067-2070.

[8] Kane,VE. Process capability indices. Journal of Quality Technology 18(1986), 41-52.

[9] Minitab Inc. (2011) Minitab User Manual Version 16, Quality Plaza, 1829 Pine Hall Road, State College, PA 16801-3008, USA.
[10] Jan wrenn Enhancing Learning by integrating theory and practice International journal of teaching and learning in higher education vol 21 2009 pp258-865 ISSN1812-9129

[11] P. Cawley, The introduction of a problem-based option into a conventional engineering degree course, Studies in Higher Education, 14 (1989), pp. 83-95

[12] J. H. Sandholtz, C. Ringstaff and D. C. Dwyer, Teaching with Technology: Creating StudentCentered Classrooms, Teachers College Press, New York (1997).

[13] D. J. Boud, Problem-Based Learning in Education for the Professions, Higher Education Research and Development Society of Australia, Sydney (1985).

[14] N.Vijayakumar Experiential Learning in Metrology and Quality Engineering Course Journal of Engineering Education Transformations, Volume 29 , No.1, July 2015, ISSN 2349-2473, eISSN 2394-1707

[15] N.Vijayakumar Attainment of higher level of blooms taxonomy through open ended activity in metrology \& quality engineering lab Journal of Engineering Education Transformations, Special Issue, eISSN 2394-1707

[16] Jangali, Satish G., and Vinayak N. Gaitonde. Attaining competencies in Programme Outcomes through Open-Ended Experiments. Africa Education Review 17, no. 1 (2020): 116140 